\title{
A psycho-educational curriculum for sport career transition practitioners: \\ Development and evaluation
}

Hee Jung Hong*\& Pete Coffee

Word count: 7,351

Author Note

Hee Jung Hong, Faculty of Health Sciences and Sport, University of Stirling, Stirling, Scotland UK

Pete Coffee, Faculty of Health Sciences and Sport, University of Stirling, Stirling, Scotland UK

This research was not supported by any funding sources.

*Correspondence concerning this manuscript should be addressed to Hee Jung Hong, Faculty of Health Sciences and Sport, University of Stirling, Stirling, UK. FK9 4LA. Email: heejung.hong@stir.ac.uk

Accepted for publication in European Sport Management Quarterly published by Taylor and Francis. 


\begin{abstract}
1. Research question: This paper is an integration of three studies. Study 1 investigates sport career transition organisational intervention programmes for high performance athletes and training and development programmes for sport career transition practitioners in order to find a research gap with regard to sport career transition supporting services. A psycho-educational curriculum was developed for sport career transition practitioner in Study 2 to fill the research gap. In Study 3, the curriculum was examined to see if the curriculum contributed to enhancing practitioners' confidence in key competences.
\end{abstract}

2. Research methods: A range of methods were applied to the studies including One Group Pre- and Post-test design, Case Study, Focus Group, Semi-Structured Interview, two-round Delphi-Method and Questionnaires. The data for Study 1 collected from 19 countries worldwide and total 16 participants based in seven different countries were invited to development and evaluation of the curriculum.

3. Results and Findings: A novel psycho-educational curriculum for sport career transition practitioner was developed and evaluated concerning four competences as a form of curriculum package. The findings revealed that the curriculum package increased the participants' confidence in key competences concerning sport career transition.

4. Implications: The findings deepen the knowledge of sport career transition in the areas of organisational intervention programmes focusing on high performance athletes and sport career transition practitioners. These findings contribute to modifying the Conceptual Model of Adaptation to Career Transition (Lavallee, Park, \& Taylor, 2014) by strengthening the organisational intervention perspective and applied work in respect of sporting organisation management strategies. 
Keywords: sport career transition organisational intervention programmes; training and development programmes; dual career transition; organisational support; sporting organisation management strategies 


\section{A psycho-educational curriculum for sport career transition practitioners:}

\section{Development and evaluation}

Research on career transition in high performance sport has gradually increased (Anderson \& Morris, 2000; Kerr \& Dacyshyn, 2000; Taylor, Ogilvie, \& Lavallee, 2005; Lally, 2007); studies on sport career transition organisational intervention programmes, however, remain scarce. Sporting organisations are arguably responsible for encouraging athletes to develop a balanced life and identity; sporting organisations can establish the proper environment for high performance athletes using athlete lifestyle programmes (Anderson \& Morris, 2000). Kossek, Pichler, Bodner, and Hammer (2011) identify two main research fields of organisational support in management literature: the relevance of organisational support to family issues and outcomes of organisational support in general (Maier, Woratscheck, \& Ströbel, 2016). In relation to high performance sport, Maier, Woratscheck, and Ströbel (2013) clarify three aspects of organisational support in high performance sport: support with the integration of players' families, support of tertiary education, and support with non-sports-related problems (Maier et al., 2016). Since Anderson's (1993) seminal study of athlete support programmes, numerous sport career transition programmes have been developed by governing bodies and sport institutes worldwide in order to assist individuals in developing a professional and academic career outside sport, as well as in achieving their sport-related goals (Lavallee et al., 2014).With regard to sport career transition programmes, Park, Lavallee, and Tod's (2013) demonstrate in their systematic review that eight studies had been conducted to date specifically on sport career transition programmes and these studies reveal positive associations between the involvement of athletes in support programmes and their life skills and quality of career transition. Existing studies on support programmes for high performance athletes do not clearly identify who delivers support services to high performance athletes. No research has 
been conducted to date that examines if and how sporting organisations train practitioners who support high performance athletes by delivering training and development programmes in sporting organisations. This paper is an integration of three studies in order to fill the gap in the literature in sport career transition.

The aim of Study 1 is to examine the following five features of sport career transition organisational intervention programmes: 1) At the government level, which organisation is responsible for the delivery of sport career transition organisational intervention programmes? 2) What are overall strategies of sport career transition organisational intervention programmes? 3) What are the activities and contents of the sport career transition organisational intervention programmes? 4) Who is responsible for the delivery of sport career transition organisational intervention programmes? and 5) Do sporting organisations have training and development programmes for sport career transition practitioners who deliver these programmes to high performance athletes? These research questions are examined in the theoretical framework of the Conceptual Model of Adaptation to Career Transition proposed by Lavallee et al. (2014) in the aspect of organisational intervention (See Figure 1). For the purposes of this study, Sports Career Transition Organisational Intervention Programmes are defined as planned programmes offered by a sporting organisation specifically designed to assist athletes in preparing for their career after sport (Lavallee et al., 2014) and practitioners are defined as people who deliver planned programmes to assist athletes in preparing for their career after sport, and include career advisors, service providers, career coaches, career counsellors, career transition advisors, dual career coordinators, project managers, support providers, life skill coaches and athlete life advisors. 
[Figure 1 near here]

In Study 2, the research question is, "What content should be included in a psychoeducational curriculum for sport career transition practitioners?" There are two stages implemented in order to demonstrate how the content of the curriculum was designed and evaluated.

In Study 3, the research question is, "How effective is the psycho-educational curriculum developed and evaluated in Study 2 in increasing sport career transition practitioners' confidence in the given key competencies?" The psycho-educational curriculum for sport career transition practitioners developed in Study 2 was examined in this study in order to answer the research question.

The purpose of the current paper is (1) to provide overview of sport career transition support programmes and training and development programmes in 19 countries worldwide as a form of organisational support for both high performance athletes and practitioners who provide support to high performance athletes, (2) to present a novel psycho-educational curriculum for practitioners aiming at making an impact on organisational support and management in order to enhance the quality of support services delivered by sporting organisations, and (3) to establish the groundwork for future studies on examining the psycho-educational curriculum by indicating significant potential with an exploratory investigation.

\section{Literature review}

High performance athletes inevitably retire; when and under which circumstances is, however, difficult to predict. Regardless of the precipitating factors, retirement is a transition and it invites identity problems and coping issues (Sinclair \& Orlick, 1994). The broad range of transitions high performance athletes encounter during their sporting career, and the 
influence of such transitions on the quality of their sport, have been comparatively neglected (Wylleman, Lavallee, \& Alfermann, 1999). Many high performance athletes are ill-prepared to retire from high performance sport, lack the resources to succeed in career transition and are thus at risk of a traumatic transition (Anderson \& Morris, 2000). Green (2006) maintains that there is need to conduct further research on identifying appropriate procedures for athletes' transitions in order to assist them in transitioning smoothly.

Research on career transitions in sport has gradually increased. In 1980, McPherson reported only 20 studies on sport career transition; by 2000, Lavallee, Wylleman, and Sinclair reported more than 270 references. Bookbinder (1955) published the first study on this topic, reporting that athletes encounter psychological, interpersonal and financial issues during their athletic career. In 2000, the first book on this subject was published, Career Transitions in Sport: International Perspectives (Lavallee \& Wylleman), followed by Athletes' Careers Across Cultures (Stambulova \& Ryba) in 2013. Park et al. (2013) provided a systematic review of 126 studies associated with career transition in sport from 1968 to 2010 . They found that, of the 126 studies, ten were published before 1990, 48 in the 1990s and 68 from 2000 to 2010. Stambulova, Alfermann, Statler, and Côté (2009) noted that athletes' career transition studies have been conducted mainly in European countries, North America, and Australia. Findings from Park et al.'s (2013) review confirmed this trend: The majority of studies were conducted in Western countries (60 in North America, 45 in Europe, and 10 in Australia). These findings greatly affect the design of Study 1, which investigated sport career transition organisational programmes in not only, North America, Europe, and Australia but across Asia, Europe, Africa, North America, South America, and Oceania. Researchers also developed and proposed a theoretical model of sport career transition in order to analyse and better understand career transition in sport (Sinclair \& Orlick, 1994; Stambulova, 1994; Wylleman \& Lavallee, 2004; Taylor et al., 2005; Lavallee 
et al., 2014). Cuskelly (2004) proposed a transition-extension proposition in order to explore and understand the transition process that athletes extend their involvement while changing their role within their sporting organisations (Cuskelly \& O’Briend, 2013).

Research has investigated how to assist high performance athletes overcome problems and crises caused by transitions. Many researchers propose that national sport organisations establish career counselling programmes for high performance athletes (Anderson \& Morris, 2000; Sinclair \& Hackfort, 2000; Wylleman et al., 1999; Taylor et al., 2005). Sporting organisations are responsible for ensuring that athletes are encouraged to develop a balanced life and identity during their sports careers (Anderson \& Morris, 2000). Although research on organisational support in high performance is limited, some researchers have investigated organisational support with specific aspects (Maier et al., 2016): welfare and education support (Drawer \& Fuller, 2002), social support (Kristiansen \& Roberts, 2010), engagement in non-athletic career (Price, Morrison, \& Arnold, 2010), and financial planning support (Nicholson, Hoye, \&Gallant, 2011). As aforementioned, Maier et al. (2013) identified three aspects of organisational support in high performance sport: integration of family, second career support, and private problem support. Maier et al. (2016) employed these three variables to their study on incentives in elite team sports in order to provide relevant knowledge about the relative effectiveness of different support services to sports managers. The result of their study demonstrated that it is crucial for organisations to create a supportive environment in line with Anderson and Morris (2000)'s argument; it also supports (a) the results on the effects of organisational support in general from non-sports-related contexts (Eisenberger, Cummings, Armeli, \& Lynch, 1997; Griffin, Patterson, \& West, 2001) and (b) the results of the qualitative studies in the sports contexts (Kristiansen \& Roberts, 2010; Nicholson, Hoye, \& Gallant, 2011). This demonstrates that organisational support plays an important role in both sport-related and non-sport-related context, which is significant for 
high performance athletes to balance between sport and non-sport careers (Anderson, 1999; North \& Lavallee, 2004; Price, Morrison, \& Arnold, 2010). Maier et al. (2016) also demonstrated that second career support, which is part of sport career transition support investigated in this paper, indicates a significant effect on performance. In relation to this, Price, Morrison, and Arnold (2010) also claim that sporting organisations and coaches should support the development of athletes as a whole person and encourage engagement in nonsporting pursuits to enhance sporting performance, career longevity and wellbeing. In addition, in Sotiriadou, Shilbury, and Quick's (2008) study of examining sport development processes in Australia, they demonstrated that sporting organisations such as the Australian Institute of Sport and state institutes and educational institutions of sport play a crucial role in the retention/transition process as those organisations provide support of skill development, physical preparation, and improved performances.

Career transition support programmes allow sporting organisations to establish an appropriate environment for high performance athletes (Anderson \& Morris, 2000). The organisational context of career development programmes is critical to assisting athletes in transition (Lavallee, Gorely, Lavallee, \& Wylleman, 2001). Based on the findings of Anderson (1993), Anderson and Morris (2000) reviewed the results of sport career transition programmes in Australia, Canada, the UK and the US, and reported that, although published research on athletic career transition and athlete education programmes began to emerge in the early 1990s, such programmes were inadequately elaborated. Lavallee et al. (2001) reviewed sport career transition organisational intervention programmes in seven countries, including Australia (Athlete Career and Education Programme, Olympic Job Opportunities Programme), Belgium (Study and Talent Education Programme), Canada (Olympic Athlete Career Centre), Netherlands (The retiring Athlete), South Africa (Olympic Job Opportunities Programme), UK (Athlete Career and Education Programme and Olympic Job Opportunities 
Programme), and US (Career Assistance Programme for Athletes, Making the Jump Programme (Advisory Resource Centre for Athletes), Women's Sports Foundation Athlete Service, Career Transition Programme, CHAMPS/Life Skills, and Making the Jump programme (Springfield College). Although the number of studies on athlete lifestyle programmes (Anderson, 1993) and career development programmes (Lavallee et al., 2001) is small, there are even fewer on sport career transition programmes worldwide and none on the features of career transition organisational interventions (Lavallee et al., 2014).

Proactive interventions are required to assist athletes in career transitions. Practitioners must therefore identify the needs of athletes at particular stages of their sport career transition process (Wylleman, Alfermann, \& Lavallee, 2004). Practitioners may need to examine coach-athlete relationships and consider enlisting the support of the coaches (Park, Lavallee, \& Tod, 2012). They also may need to employ different kinds of assistance to support these young athletes as they withdraw from their sport, such as helping them minimise feelings of failure and self-disappointment by establishing a positive self-image and self-confidence. In addition, many athletes did not participate in career transition intervention programmes, even when they had the opportunities (Albion, 2007; Lavallee, 2005). Practitioners need to educate such athletes on the importance of pre-transition planning and life skills development (Park et al., 2012). Maier et al. (2016) also indicated, in their study of investigating the relationships among monetary incentives, organisational support, and athletic performance in elite team sports, that club managers need to know which incentive can contribute to enhancing athletes' overall job satisfaction; they conclude that nonmonetary incentives such as integration of family, second career support, and private problem support play a key role in creating a performance-oriented environment within elite sport clubs. Although it is identified that practitioners play an important role in delivering sport career transition programmes to high performance athletes, no research has been published on 
training and development programmes for sport career practitioners. This could be significant given the amount of research focusing on high performance athletes (Park et al., 2013), who often require career transition organisational intervention programmes and the services provided by practitioners.

In the theoretical framework for adaptation to sports career transition proposed by Lavallee et al. (2014, See Figure 1), five interventions are proposed to assist high performance athletes overcome retirement crisis: cognitive, emotional, behavioural, social and organisational interventions. This paper focuses on organisational interventions in order to advance theory and knowledge in this area and assist sport career transition practitioners and sport organisations in their responsibility to support athletes in transition.

As aforementioned, this paper is an integration of three studies so each study is presented in detail.

\section{Study 1 \\ Methods}

This study focuses on sport career transition organisational intervention programmes for high performance athletes and training and development programmes for sport career transition practitioners in different countries. Country-specific cross-country analyses were conducted, based on Lavallee et al. (2014).

Data collection was conducted between November 2013 and October 2014. Data collection was initiated by examining the International Olympic Committee and National Olympic Committee websites in order to identify relevant websites of sporting organisations offering sport career transition programmes that met the inclusion criteria: that is, that could be used to investigate the research questions stated earlier. Web-based data collection was conducted first. The first author contacted the sporting organisations to clarify information as required by requesting further information via emails, international calls, video calls on 
Skype, faxes and by visiting the sporting organisation and meeting with the practitioners (Centre d'alt Rendiment; CAR in Catalan, Barcelona, Spain). Data was initially collected from 23 countries; that from 19 countries was used for the final analysis (Australia, Belgium, Brazil, Canada, Denmark, France, Germany, Ireland, Japan, Netherlands, New Zealand, Russia, South Africa, South Korea, Spain, Sweden, Switzerland, UK, US). Although the four countries omitted were periodically contacted at least five times or more for each within the time of the data collection, they were omitted on the list of the data collection because they did not respond to the emails and provide insufficient information to answer the research questions on their websites. The data collected was organised according to the research questions and sent to the practitioners to be confirmed before analysing the data.

\section{Results and Discussion}

Question 1: At the government level, which organisation is responsible for the delivery of sport career transition organisational intervention programmes?

The findings indicate that the National Olympic Committees in each country are responsible for the delivery of the majority (11 countries) of sport career transition organisational intervention programmes (Brazil, Belgium, Germany, Japan, Netherlands, South Africa, South Korea, Spain, Sweden, Switzerland and the US). Ten countries (Australia, Belgium, Canada, Denmark, France, Ireland, New Zealand, South Korea, Spain, and the UK) have sporting organisations responsible for sport career transition programmes independent of their National Olympic Committees.

Three countries (Belgium, South Korea and Spain) have more than two different sport career transition programmes, respectively, offered by the National Olympic Committees and the other sporting organisations in one country. The UK has four different sporting organisations (the EIS, Sportscotland institute of Sport, Sportwales and Sports institute Northern Ireland) based in each home country. Belgium has two different sporting 
organisations (BLOSO and ADEPS) independent of the Belgian Olympic Committee based on each community in Belgium (BLOSO: Flemish-speaking community and ADEPS: French-speaking community); in Spain, Centre d'alt Rendiment (CAR) is a sporting organisation located in Catalonia and funded by the Catalan federation, which offers this programme to Catalan athletes.

With regard to EU countries (Belgium, Denmark, France, Germany, Ireland, Netherlands, Spain, Sweden and the UK), Dual Careers developed by the EU is implemented in Belgium (ADEPS), Denmark (Team Denmark), France (INSEP), Germany (DOSB) and the Netherlands (NOC*NSF; Gold on the workfloor is delivered in association with Dual Careers).

11 National Olympic Committees offer sport career transition programmes for high performance athletes (Brazil, Belgium, Germany, Japan, Netherlands, South Africa, South Korea, Spain, Sweden, Switzerland and the US). Among the 11 National Olympic Committees, five countries (Brazil, Belgium, South Africa, Switzerland and the US) offer the Athlete Career Programme developed by the International Olympic Committee; the rest of the countries run different programmes: Germany (Dual Careers), Japan (Career Academy), Netherlands (Gold on the work floor), South Korea (Retired Athletes Support Portal), Spain (Oficina de Atención al Deportista) and Sweden (the High Performance Support Programme).

Question 2: What are overall strategies of sport career transition organisational intervention programmes?

Most programmes focus on assisting athletes in balancing their sporting career with the other areas in their lives by offering educational, vocational, personal development, career development and life skills support services. However, the programmes of New Zealand, Sweden and the US also emphasised that they intend to help athletes enhance their high 
performance as a result of their involvement in the programmes.

In terms of whether a programme is proactive or reactive, all the programmes are proactive except for the programme in South Korea. This is because the career transition programmes offered by the KOC and the NEXT foundation in South Korea are designed only for retired athletes. This finding is consistent with the perspective the specific needs of athletes should be supported proactively owing to the importance of pre-transition planning and life skills development (Gilmore, 2008; Park et al., 2012; Wylleman et al., 2004). Offering proactive support services during the early stages of the retirement process might effectively assist athletes; practitioners can assist athletes with strategies tailored to their current stage in the retirement process (Park et al., 2012).

Question 3: What are the activities and contents of the sport career transition organisational intervention programmes?

A majority of sport career transition organisational intervention programmes offer career counselling in the form of psychological support, career planning, academic advices and job preparation.

High performance athletes require customised support services (Petitpas \& Champagne, 2000; Park et al., 2012). 13 sporting organisations from 12 countries reviewed here offer tailored support services (Australia, Belgium, Canada, Denmark, France, Germany, Japan, New Zealand, Spain, Sweden, the UK (Sportscotland and Sportwales) and the US) as part of their sport career transition organisational intervention programmes. Although the remaining sporting organisations did not specifically mention that they offer a customised service, their support service can be considered tailored, as practitioners work closely with individual athletes and offer what the athlete needs within the programme resources.

Since high performance athletes need to train in different environments depending on their training schedule, they are not always available to access offline programmes. Petitpas 
and Champagne (2000) argued that the use of online inventories, job search resources and Internet career information during intervention programmes not only enhances workshop offerings, but also provides information to participants about how to access career information at other sites after completing the sport career transition programme. Five sporting organisations from four countries offer online support services (Australia, Canada, South Africa and South Korea (both the KOC and the NEXT foundation) because high performance athletes often travel to train and compete.

Question 4: Who is responsible for the delivery of sport career transition organisational intervention programmes?

14 sporting organisations from 13 countries have specific practitioners for their programmes: Australia (ACE advisors), Belgium (BLOSO: two Career Counsellors and a sport psychologist inside of the organisation and eight Career Counsellors as partners outside of the organisation, ADEPS: two experts of the education sector, one career advisor, and one coordinator), Canada (Athlete Career Transition Advisors), Denmark (a Dual Career Coordinator), Germany (a Project Manager and Career Advisors), Ireland (Support Providers), Netherlands (Career Counsellors, Study Coaches and Topsport Life Skills Coaches), New Zealand (Athlete Life Advisors), Spain (CAR: the Mentors of residence and SAE Advisors), Sweden (A group of coordinators and a resource team), Switzerland (a Career Advisor and a Head of Performance), the UK (Athlete Advisors) and the US (Career Coaches). Two Asian countries (Japan and South Korea) do not have specific practitioners for their programmes; staff from other sporting organisations (JOC, KOC and the NEXT foundation) delivers their programmes to high performance athletes. Unfortunately, data collected on practitioners who deliver the programmes directly in the rest of programmes in other countries (Brazil, France, South Africa and Spain (OAD)) was insufficient to determine who exactly is involved in the delivery of sport career transition organisational intervention 
programmes. Adecco, a global leader in Human Resources services, is closely involved in the delivery of the sport career transition programme in Sweden, Switzerland, and the US.

Question 5: Do sporting organisations have training and development programmes for sport career transition practitioners who deliver these programmes to high performance athletes?

Seven sporting organisations have developed an explicit training programme for practitioners who deliver sport career transition organisational intervention programmes: Australia, Belgium (BLOSO), Ireland, New Zealand, Sweden, the UK and the US. Four sporting organisations support sport career practitioner development by providing courses and internal conferences/workshops: Australia, New Zealand, South Korea and the UK (Scotland). Of these, the Australian institute of Sport (Australia) and the Swedish Olympic Committee (Sweden) require their practitioners to hold a certification that qualifies them for their career as a sport career transition organisational intervention programme practitioner. Two organisations (Canada and Japan) reported plans for a certificate programme.

Anderson and Morris (2000) investigated the athlete lifestyle programmes from Australia, Canada, the UK and the US based on visiting sporting centres. Lavallee et al. (2001) studied 11 career development programmes in seven countries. Compared to those results, 21 programmes from 18 countries included in the current study (Russia was the exception) are implemented at present. Ten countries (Australia, Belgium, Canada, Denmark, France, Ireland, New Zealand, South Korea, Spain and the UK) have their own sporting organisations, which are responsible for career transition programmes independently of their National Olympic Committees. According to Anderson and Morris (2000), sporting organisations should ensure that athletes develop a well-rounded approach to life, one that encourages them to expand their identity beyond sport. Athlete lifestyle programmes can allow sporting organisations to establish the best environment for athletes. 
$89 \%$ of sport career transition organisational programmes in the current study offer proactive career transition programmes; only two programmes from South Korea provide reactive programmes. Researchers in sport career transition (Gilmore, 2008; Wylleman et al., 2004; Park et al., 2012) have emphasised proactive interventions. However, longitudinal studies (Douglas \& Carless, 2009; Lally, 2007) indicate that athletes demonstrate changes in their degree of athletic identity and require time to adjust to their post-sport lives; therefore, to assist athletes in sport career transition, practitioners must provide both proactive (career planning, education in transferable skills) and reactive (coping with emotions, supporting the identity reformation process) programmes support (Park et al., 2012).

The current study proposes that sport career transition practitioners play an important role in making high performance athletes aware of the support services and involving coaches, athletes' parents and academic advisors as well as high performance athletes themselves in sport career transition organisational intervention programmes. The findings of this study show that sport career practitioners work closely with high performance athletes while treating them as individuals and contacting people close to athletes to manage both their sporting and non-sporting careers.

International comparisons of career transition programmes remain nascent. In this study, it is hoped that areas of convergence have been identified, leading to a more systematic understanding. By selecting comparable career transition organisational intervention programmes, the current study reviews programmes worldwide, characterising their similarities, differences and difficulties, so that sporting organisations and practitioners might improve sport career transition organisational intervention programmes. Although a large number of career transition organisational intervention programmes have been investigated in this study, countries not included here may have developed unique programmes. 
There is a paucity of research on practitioner training programmes. This topic could attract attention from researchers, sporting organisations, stakeholders and practitioners themselves, as practitioners are the ones who closely work with high performance athletes, a major reason why they deliver such programmes effectively. More attention should be paid to designing a training and development programme for sport career practitioners who deliver sport career transition organisational intervention programmes. Although this study investigates a large number of training and development programmes for sport career practitioners, it is possible that countries excluded from this study might have developed their own practitioner-specialised training and development programmes that fit the criteria of the current study.

\section{Study 2}

\section{Methods}

In this study, two stages are conducted to demonstrate how the content of the psychoeducational curriculum was designed and evaluated.

\section{Stage 1: Curriculum Design}

A curriculum was initially developed based on the following five themes that emerged from the extant literature and the findings from Study 1: Career Transitions in Sport; Sport Career Transition Management; Sport Career Transition Counselling; Sport Career Transition Professional Practice; and Research Skills.

\section{Stage 2: Curriculum Evaluation}

Design

A two-round Delphi method was chosen to evaluate the initial psycho-educational curriculum developed for this study. Delphi methods are employed to explore an area of future thinking that goes beyond what is currently known or believed (Iqbal \& Pipon-Young, 2009; Skulmoski, Hartman, \& Krahn, 2007). Delphi methods work well when studies aim at 
improving understanding of opportunities, challenges, solutions, or developing forecasts on the chosen research topic (Skulmoski et al., 2007). Also, the reliability and validity of the study is improved if an initial group of experts produces the items. Panellists form the lynchpin of the Delphi, and clear inclusion criteria should be applied and outlined as a means of evaluating the results and establishing the potential relevance of their study to other settings and populations. The number of panellists depends greatly on the topic area as well as on the time and resources at the researchers' disposal (Iqbal \& Pipon-Young, 2009). In general, a varied panel is considered best in producing a valid questionnaire and individuals who might provide a minority or differing perspective should be actively recruited to the panel (Linstone \& Turoff, 2002). Panellists are often recruited via letter e-mail or snowballing (asking panellists to pass on invitations to other relevant individuals; Iqbal \& Pipon-Young, 2009). This method was chosen for this study by sufficient discussions with a leading expert in this area along with investigating a variety of methods including Delphi method in order to find the best fit to this study and ensure the credibility and validity of the method. In this regard, Delphi method was employed to Costa (2005)'s study of identifying the status and future of sport management and a panel of leading scholars in sport management worldwide were invited to the study. In this study, sport management scholars managed to explore constructive ways to contribute to the development of the field of sport management as a result of engaging in discussions on the topic of the status and future of sport management (Costa, 2005).

\section{Participants}

In the Delphi method, expert panel members are selected to maximise expertise (Ziglio, 1996). In this study, eight expert panel members were recruited from different countries. The selection criteria for panellists were as follows: 1) having researched and published in the area of sport career transition for at least five years (minimum two 
panellists), 2) having provided sport career transition support service for sporting organisations for at least five years (minimum two panellists), 3) having competed or recently retired from competing at an international level as a high performance athlete (minimum two panellists) and 4) having worked for at least five years in this area as a career transition expert outside sport (minimum one panellist). The panel in this study included two researchers (one female and one male), three sport career transition practitioners (two females and one male), two high performance athletes (one current male and one retired female), and one career coaching expert from outside sport (female). At the time of the study, participants were based in Australia, Ireland, New Zealand, South Korea and the UK. All panel members were invited by email to participate in this study.

\section{Procedure}

There were two rounds in this study. All panel members were assured anonymity and confidentiality. In Round 1, the panel members were provided with a copy of the curriculum and asked to comment on each part of the curriculum and anything else. In Round 2, the panel members were asked to provide both quantitative and qualitative data as well as an Expert Review Likert Questionnaire.

\section{Analysis}

In Round 1, thematic analysis was conducted on the data collected from the eight panel members as well as on the results from Study 1 and the literature review. Thematic analysis is a method for identifying, analysing and reporting patterns (themes) in data as well as for organising and describing data (Braun \& Clarke, 2006). This method can also be used to interpret various aspects of the research topic (Boyatzis, 1998). Thematic analysis is the method best suited to establish the relationships among the findings from Study 1, the literature review and the data from the current study. 
After collecting feedback from all panel members, both quantitative and qualitative methods of analysis were performed in Round 2. The overall percentage of each section of the Likert scale was calculated. Thematic analysis was used to analyse the open-ended questions in Round 1.

\section{Results and Discussion}

\section{Stage 1: Curriculum Design}

There are five themes in the results as follows: Career transitions in Sport; Sport Career Transition Management; Sport Career Transition Counselling; Sport Career Transition Professional Practice; and Research Skills. Based on the results of Study 1, as well as the literature review, the content for the curriculum was structured as a series of programmes for postgraduate study. An initial psycho-educational curriculum for sport career transition practitioners was developed for the evaluation phase. Research Skills was considered as part of the development. The curriculum was comprised of six sections: 1) Summary of the curriculum, 2) Aims of the curriculum, 3) Intended learning outcomes, 4) Modules, 5) Module details and 6) Core texts of the curriculum.

\section{Stage 2: Curriculum Evaluation}

In Round 1, six themes were identified: understand high performance environment; assist in balancing sporting career and non-sporting career; transitional support; psychological support: counselling, consulting, and mentoring; provide customised programmes; and qualification for a sport career transition practitioner. In Round 2, two themes were identified: employability and subject-specific content. On analysis of data gathered using the Likert-type scale, panel members selected Strongly Agree (31.25\%), Agree (50\%) or Agree somewhat (18.75\%) in seven of the eight sections. However, the opinions of the experts differed on the module of Sport Career Transition Professional Practice: Strongly Agree (12.5\%), Agree (37.5\%), Agree somewhat (12.5\%) and Undecided 
(37.5\%). Nevertheless, the members agreed that the psycho-educational curriculum is expected to contribute to career development and training for sport career transition practitioners. A final version of the psycho-educational curriculum for sport career transition practitioners is presented in Table 1.

[Table 1 near here]

The present study aimed to develop a new psycho-educational curriculum for sport career transition practitioners based on the results from the previous study, as well as on the literature review, and to evaluate such a curriculum. The psycho-educational curriculum can be adapted to different countries, depending on sport policy, sporting organisations, culture and special needs. However, it is recommended that the structure and key content of the psycho-educational curriculum are retained, as these were developed based on data from previous study from 19 countries worldwide and on the existing literature on this topic.

The present study contributes to the theoretical framework of the Conceptual Model of Adaptation to Career Transition (Lavallee et al., 2014) by strengthening the organisational intervention aspect. Since the curriculum was designed mainly for practitioners working in sporting organisations, the career development of the practitioner by the curriculum is expected to enhance the delivery quality of organisational intervention support services. This will affect Healthy Career Transition of high performance athletes within the theoretical framework of the Conceptual Model of Adaptation to Career Transition. One of the objectives of providing support services is to assist high performance athletes in managing their career development and optimising their potential in other aspects of their lives by providing multi-format support services such as counselling, written information and skills enhancement programmes. The psycho-educational curriculum provides an opportunity to acquire the knowledge and practical skills considered important in the literature. Anderson and Morris (2000) insisted that sporting organisations have a responsibility to assist high 
performance athletes in balancing their sporting and non-sporting careers. As this curriculum was developed based on the aspect of organisational intervention in the Conceptual Model of Adaptation to Career Transition theoretical framework, it is expected to attract attention from sporting organisations worldwide and made an impact on sporting organisation management strategies with regard to organisational support. Practical implications for practitioners, such as providing both proactive and reactive support, examining the coach-athlete relationship, helping athletes reduce negative feelings induced by their sporting careers ending and improving self-image and self-confidence were identified in literature (Park et al., 2012). These implications are included in the details of the psycho-educational curricula modules for sport career transition practitioners in this study.

Since this study represents a first attempt at designing a curriculum in this field, it must be evaluated and potentially adjusted to be a better fit for potential applicants worldwide. Some of the modules in the final version will therefore be examined in the next study as an exploratory investigation. Delivery of the curriculum will take the form of blended learning, completing modules online and having a residential week during a semester. The campus-based residential week is comprised of workshop-based activities. Therefore, some modules that can be designed for workshops will be examined in the next study.

\section{Study 3}

\section{Methods}

This study is an exploratory investigation with an aim of examining the psychoeducational curriculum developed and evaluated in Study 2 in order to demonstrate how effective the curriculum is in increasing sport career transition practitioners' confidence in the given key competencies. Exploratory research is the preferred methodological approach when little or no systematic empirical examination has been applied to the phenomenon 
(Stebbins, 2001, 2008) and has flexibility with regard to methods used to gain new insights into the phenomena and develop hypotheses (Churchill 1999; Speed \& Thompson, 2000; Vanhamme, 2000). This approach is, therefore, considered as appropriate because the psycho-educational curriculum has not been examined.

Design

The final study employed a One-Group Pre- and Post-design (Dimitrov \& Rumrill, 2003), with a single pre-test measurement taken, intervention implemented and post-test measurement taken.

\section{Participants}

There were four participants (two males and two females based in Ghana, Lithuania, and the UK). Three participants held either Masters or Ph.D. degrees in sport psychology and had an interest in careers related to sport career transition. The last participant was a sport career transition practitioner at the time of the study. Each participant is considered as a case in this study.

\section{Procedure}

Participants were invited to complete a questionnaire to assess their confidence in four key competencies areas (i.e., Dual Career Transition Management, Skill Transfer, Social Support and Career Planning; see Wylleman, De Brandt, \& Defruyt, 2017). Subsequently, a curriculum portal for this study was introduced to participants, where they were invited to work through the curriculum package developed for this study in order to test the psychoeducational curriculum for sport career transition practitioners developed in Study 2. The curriculum package consisted of six sections that were selected from the original curriculum for the purpose of this study as core contents. Six sections of the curriculum were investigated in this study: Introduction, Part 1 (Key Readings and Video Resources), Part 2 (Case Study), Part 3, Section1 (Writing a dual career athlete CV), Part 3, Section2 (Dual 
Career SWOT Analysis) and Part 3, Section3 (Dual Career SWOT strategies guideline). Each post was password-protected so that only participants could review their own posts.

Participants were allocated two weeks to work through the six sections of the curriculum package. Participants were then invited to complete the same questionnaire they did at the outset at the end of the study in order to assess the changes of the participants' confidence in the four competences between before and after completing the curriculum package. Analysis

Participants completed the competencies questionnaire before and after completing the psycho-educational curriculum package on the curriculum portal for this study. A comparative analysis was performed on the pre- and post-questionnaires participants completed by calculating the means of each competency.

\section{Results and Discussion}

The mean of each competency was calculated for pre- and post-test to determine the difference between pre- and post-test. This facilitated a clear demonstration of how much the confidence of the participants increased and how effective the curriculum package is. For all four participants, differences between pre- and post-test scores on all competences were positive and significant, indicating that the curriculum package effectively assists participants in enhancing their confidence in Dual Career Transition Management, Skill Transfer, Social Support and Career Planning. Results indicated that all participants have greater confidence across the four competences after completing the psycho-educational curriculum package. The results are presented in Table 2 .

[Table 2 near here]

With regard to the role of practitioners, the need to provide proactive interventions to assist athletes with career transitions has been emphasised (Lavallee et al., 2014). In order to do so, practitioners need to identify the needs of individual athletes at specific stages during 
their career transition (Wylleman et al., 2004). For active athletes with negative perceptions of support programme involvement, practitioners need to provide education related to the importance of pre-transition planning and life skills development (Park et al., 2012). Career development programmes provide athletes with an introduction to career planning and development by focusing on their values and exploring their interests, career awareness and decision-making skills, CV preparation, interview experience, techniques and job search strategies (Lavallee et al., 2001). These indicate that competencies in Career Planning are crucial for sport career transition practitioners. However, the pre- and post-test questionnaire differences on the remaining three competences were similar. The majority of career transitions and athlete life skill programmes focus on lifestyle management and on the development of transferable skills to assist individuals in making the transition from life in sport to a post-sport career (Wylleman et al., 2004). Transition programmes should be multidimensional and include enhancement, support and counselling components (Petitpas, Brewer, \& Van Raalte, 1996). Practitioners should be encouraged to teach retiring and retired athletes life skills that help them achieve success outside sport (Petitpas \& Schwartz, 1989). In line with the need of multidimensional support for high performance athletes, it is worth noting that the psycho-educational curriculum for sport career transition practitioners examined in this study delivers the modules of Career Transition in sport, Sport Career Management, Sport Career Transition Counselling, and Sport Career Transition Professional Practice; these modules aim at having practitioners equipped with knowledge, experiences, and skills in the field of sport management and sport psychology linked to sport career transition support, which will enable them to provide theory-based, practical, multidimensional support to high performance athletes.

The results suggest that the psycho-educational curriculum contributes to the career development and improvement of sport career transition practitioners once they complete the 
entire psycho-educational curriculum. The curriculum package contributes to developing and enhancing the four competencies which strongly indicates its efficacy in developing sport career transition practitioner competencies. Since the current study is an exploratory investigation, the sample was small, which limits the generalisability of the results. If the purpose of a study is to generalise findings across different types of organisations or countries, then a heterogeneous sample must be considered (Short, Ketchen Jr, \& Palmer, 2002). However, the objective of this study was not to generalise the findings but highlight the potential of the psycho-educational curriculum in order to enhance practitioners' confidence across given competences. The current study was also to direct a possible future research in relation to examining the original curriculum applying a larger sample size. Therefore, future research with a larger sample or that allows sport career transition practitioners to complete the curriculum is required.

The current study enriches the sparse literature on training and development support programmes for practitioners who deliver such programmes. Researchers should explore ways that practitioners might apply their research findings in work with athletes (Wylleman et al., 2004). It is also hoped that the current study will contribute to the development of sport career transition practitioner competences.

\section{Conclusion}

Research on the development and evaluation of curricula for practitioners in sport is limited (cf. Gordon, Potter, \& Ford, 1998). This paper aims to contribute to the literature on sport career transition and to develop and evaluate a psycho-educational curriculum that sporting organisations and educational institutions can apply to practice worldwide. The findings suggest several directions for improving sport career transition organisational intervention programme delivery. 
Three studies presented in this paper have contributed to the sport career transition literature and applied work in in respect of sporting organisation management strategies by (1) providing an overview of a broad range of sport career transition organisational intervention programmes for high performance athletes and training and development programmes for sport career transition practitioners; (2) offering a new perspective on sport career transition, focusing on not only high performance athletes but also sport career transition practitioners; (3) presenting a psycho-educational curriculum for sport career transition practitioners that sporting organisations worldwide can employ to their supporting services management strategies and (4) providing a number of strong possibilities for future research.

This paper has great potential to contribute to the career development of sport career transition practitioners by offering a well-developed and specialised curriculum. The delivery quality of the sport career transition organisational intervention programmes worldwide can be enhanced to support high performance athletes in making more positive career transitions. The present studies are also designed to strengthen relevant theories by expanding the organisational intervention aspect of Lavallee et al.'s (2014) model as well as making an impact on sporting organisations management in respect of providing on-going personal development programmes to both high performance athletes and their employees, sporting career transition practitioners.

This empirical study will hopefully enable sporting organisations and educational institutions relating to sport career transition to apply this new theoretical knowledge and practical psycho-educational curriculum in order to support both high performance athletes and sport career transition practitioners. 


\section{References}

Albion, M.J. (2007). Restoring the balance: Women's experiences of retiring from elite sport. Paper presented at the International Women's Conference: Education, Employment and Everything...the triple layers of a Woman's Life, Toowooma, Queensland, Australia. Retrieved from: http://eprints.usq.edu.au/3447/

Anderson, D. (1993). Research tour - Elite Athlete Education Programs. Melbourne: Victorian Institute of Sport.

Anderson, D., \& Morris, T. (2000). Athlete lifestyle programs. In D. Lavallee \& P. Wylleman (Eds.), Career transitions in sport: International perspectives (pp. 59-80). Morgantown, WV: Fitness Information Technology.

Bookbinder, H. (1955). Work histories of men leaving a short life span occupation. Journal of Counseling \& Development, 34(3), 164-167.

Boyatzis, R. (1998). Transforming qualitative information: Thematic analysis and code development. Thousand Oaks, CA: Sage.

Braun, V. and Clarke, V. (2006) Using thematic analysis in psychology. Qualitative Research in Psychology, 3(2), 77-101.

Churchill, G. A (1999). Marketing Research: Methodological Foundations (7th Ed.). Orlando: The Dryden Press.

Costa, C. A. (2005). The status and future of sport management: A Delphi study. Journal of Sport Management, 19(2), 117-142.

Cuskelly, G. (2004). Volunteer retention in community sport organisations. European sport management quarterly, 4(2), 59-76.

Cuskelly, G., \& O'Brien, W. (2013). Changing roles: applying continuity theory to understanding the transition from playing to volunteering in community sport. European sport management quarterly, 13(1), 54-75. 
Dimitrov, D. M., \& Rumrill Jr, P. D. (2003). Pretest-posttest designs and measurement of change. Work, 20(2), 159-165.

Douglas, K., \& Carless, D. (2009). Abandoning the performance narrative: Two women's stories of transition from professional sport. Journal of applied sport psychology, 21(2), 213-230.

Drawer, S., \& Fuller, C. (2002). Perceptions of retired professional soccer players about the provision of support services before and after retirement. British Journal of Sports Medicine, 36(1), 33-38.

Eisenberger, R., Cummings, J., Armeli, S., \& Lynch, P. (1997). Perceived organizational support, discretionary treatment, and job satisfaction. Journal of Applied Psychology, $82(5), 812-820$.

Gilmore, O. (2008). Leaving competitive sport: Scottish female athletes' experiences of sport career transitions (Unpublished doctoral dissertation). The University of Stirling, Scotland, UK.

Gordon, S., Potter, M., \& Ford, I. W. (1998). Toward a psychoeducational curriculum for training sport-injury rehabilitation personnel. Journal of Applied Sport Psychology, 10(1), 140-156.

Green, M. (2006). From 'sport for all'to not about 'sport'at all?: Interrogating sport policy interventions in the United Kingdom. European sport management quarterly, 6(3), 217238.

Griffin, M. A., Patterson, M. G., \& West, M. A. (2001). Job satisfaction and teamwork: The role of supervisor support. Journal of Organizational Behavior, 22(5), 537-550.

Iqbal, S., \& Pipon-Young, L. (2009). Methods-The Delphi method--A guide from Susanne Iqbal and Laura Pipon-Young. Psychologist, 22(7), 598. 
Kerr, G., \& Dacyshyn, A. (2000). The retirement experiences of elite, female gymnasts. Journal of applied sport psychology, 12(2), 115-133.

Kossek, E. E., Pichler, S., Bodner, T., \& Hammer, L. B. (2011). Workplace social support and work-family conflict: A meta-analysis clarifying the influence of general and workfamily-specific supervisor and organizational support. Personnel psychology, 64(2), 289313.

Kristiansen, E., \& Roberts, G. C. (2010). Young elite athletes and social support: Coping with competitive and organizational stress in "olympic" competition. Scandinavian Journal of Medicine and Science in Sports, 20(4), 686-695.

Lally, P. (2007). Identity and athletic retirement: A prospective study. Psychology of sport and exercise, 8(1), 85-99.

Lavallee, D. (2005). The effect of a life development intervention on sports career transition adjustment. Sport Psychologist, 19(2), 193-202.

Lavallee, D., Gorely, T., Lavallee, R., \& Wylleman, P. (2001). Career development programs for athletes. In W. Patton , \& M. McMahon (Eds.), Career development programs:Preparation for life long career decision making (pp. 125-133). Camberwell, VIC: Australian Council for Educational Research Press.

Lavallee, D., Park, S., \& Taylor, J. (2014). Career transition among athletes: Is there life after sports?. In J. Williams \& V. Krane (Eds.), Applied sport psychology: Personal growth to peak performance (pp. 490-509). New York, US: McGraw-Hill.

Lavallee, D., \& Wylleman, P. (2000). Career transitions in sport: International perspectives. The United States of America: Fitness Information Technology.

Lavallee, D., Wylleman, P., \& Sinclair, D. A. (2000). Career transitions in sport: An annotated bibliography. In D. Lavallee \& P. Wylleman (Eds.), Career transitions in 
sport: International perspectives (pp. 207-258). Morgantown, WV: Fitness Information Technology.

Linstone, H. A., \& Turoff, M. (2002). The Delphi Method: Techniques and Applications. Retrieved from http://is.njit.edu/pubs/delphibook

Maier, C., Woratschek, H., \& Strobel, T. (2013). Performance measurement in sport organisations - an exploratory study of non-monetary incentives in professional team sports. Proceedings of teh 21st EASM Conference, Istanbul.

Maier, C., Woratschek, H., Ströbel, T., \& Popp, B. (2016). Is it really all about money? A study on incentives in elite team sports. European Sport Management Quarterly, 16(5), $592-612$.

McPherson, B. D. (1980). Retirement from professional sport : The process and problems of occupational and psychological adjustment. Sociological Symposium, 30, 126-143.

Nicholson, M., Hoye, R., \& Gallant, D. (2011). The provision of social support for elite indigenous athletes in Australian football. Journal of Sport Management, 25(2), 131142.

North, J., \& Lavallee, D. (2004). An investigation of potential users of career transition services in the United Kingdom. Psychology of Sport and Exercise, 5(1), 77-84.

Park, S., Lavallee, D., \& Tod, D. (2012). The development of an athlete career transition programme: A case study. QMiP Bulletin, 13, 11-19.

Park, S., Lavallee, D., \& Tod, D. (2013). Athletes' career transition out of sport: A systematic review. International Review of Sport and Exercise Psychology, 6(1), 22-53.

Petitpas, A., Brewer, B.W., \& Van Raalte, J.L. (1996). Transitions of the student-athlete: Theoretical, empirical, and practical perspectives. In E.F. Etzel, A.P. Ferrante, \& J.W. Pinkney (Eds.), Counseling college student-athletes: Issues and interventions (pp. 137156). Morgantown, WV: Fitness Information Technology. 
Petitpas, A., \& Champagne, D. (2000). Practical considerations in implementing sport career transition programs. In D. Lavallee, \& P. Wylleman (Eds.), Career Transitions in Sport: International Perspective (pp.81-93). Morgantown, WV: Fitness Information Technology.

Petitpas, A., \& Schwartz, H. (1989). Assisting student athletes in understanding and identifying transferable skills. The Academic Athletic Journal, 6, 37-42.

Price, N., Morrison, N., \& Arnold, S. (2010). Life out of the limelight: Understanding the nonsporting pursuits of elite athletes. International Journal of Sport \& Society, 1(3), 6979.

Short, J. C., Ketchen Jr, D. J., \& Palmer, T. B. (2002). The role of sampling in strategic management research on performance: A two-study analysis. Journal of Management, $28(3), 363-385$.

Sinclair, D. A., \& Hackfort, D. (2000). The role of sport organization in the career transition process. In D. Lavallee, \& P. Wylleman (Eds.), Career Transitions in Sport: Internatinal Perspectives (pp. 131-142). Morgantown, WV: Fitness Information Technology, Inc.

Sinclair, D. A., \& Orlick, T. (1994). The effects of transition on high performance sport. In D. Hackfort (Ed.), Psycho-social issues and interventions in elite sports (pp. 29-55). Frankfurt: Lang.

Skulmoski, G., Hartman, F., \& Krahn, J. (2007). The Delphi method for graduate research. Journal of Information Technology Education: Research, 6(1), 1-21.

Sotiriadou, K., Shilbury, D., \& Quick, S. (2008). The attraction, retention/transition, and nurturing process of sport development: Some Australian evidence. Journal of sport management, 22(3), 247-272.

Speed, R., \& Thompson, P. (2000). Determinants of sports sponsorship response. Journal of the Academy of Marketing Science, 28(2), 226-238. 
Stambulova, N. B. (1994). Developmental sport career investigations in Russia: A postperestroika analysis. The Sport Psychologist, 8(3), 221-237.

Stambulova, N., Alfermann, D., Statler, T., \& Côté, J. (2009). ISSP position stand: Career development and transitions of athletes. International Journal of Sport and Exercise Psychology, 7(4), 395-412.

Stambulova, N. B., \& Ryba, T. V. (2013). Athletes' careers across cultures. East Sussex: Routledge.

Stebbins, R (2001). Exploratory research in the social sciences. Thousand Oaks, CA: Sage. doi: $10.4135 / 9781412984249$

Stebbins, R. (2008). Exploratory research. In Lisa M. Given (Ed.), The Sage encyclopaedia of qualitative research methods. (pp. 327-331). Thousand Oaks, CA: Sage. doi: 10.4135/9781412963909.n166

Taylor, J., Ogilvie, B., \& Lavallee, D. (2005). Career transition among elite athletes: Is there life after sports? In J. M. Williams (Ed.), Applied sport psychology: Personal growth to peak performance (pp. 595-615). Columbus, OH: McGraw-Hill.

Vanhamme, J. (2000). The link between surprise and satisfaction: an exploratory research on how best to measure surprise. Journal of Marketing Management, 16(6), 565-582.

Wylleman, P., Alfermann, D., \& Lavallee, D. (2004). Career transitions in sport: European perspectives. Psychology of Sport and Exercise, 5(1), 7-20.

Wylleman, P., De Brandt, K., \& Defruyt, S. (2017). GEES Handbook for Dual Career Support Providers. Retrieved from http://www.gees.eu

Wylleman, P., \& Lavallee, D. (2004). A developmental perspective on transitions faced by athletes. In M. Weiss (Ed.), Developmental sport psychology (pp.507-527). Morgantown, WV: Fitness Information Technology. 
Wylleman, P., Lavallee, D., \& Alfermann, D. (1999). Transitions in the career of competitive athletes. Lund, Sweden: FEPSAC.

Ziglio, E. (1996). The Delphi method and its contribution to decision-making. In M. Adler, \& E. Ziglio (Eds.), Gazing into the oracle: The Delphi method and its applications to social policy and public health (pp. 3-33). Bristol, PA: Jessica Kingsley. 


\section{Tables}

Table 1

Psycho-educational curriculum for sport career transition practitioners

\section{Section 1: Summary of the curriculum:}

The Curriculum in Sport Career Transition Management is a highly specialised programme designed for individuals who are interested in a career as a sport career transition practitioner who supports athletes experiencing transitions throughout their sport career including preparing for life after sport. Students are expected to understand the process of career transitions that high performance athletes go through during their sporting career. Also, students acquire both academic and practical approaches and application in order to effectively offer sport career transition support to high performance athletes by learning the specific skills such as Time management/Goal setting, Career/Life Coaching, and Mentoring.

\section{Section 2: Aims of the curriculum}

- Provide the knowledge and skills required for students to pursue a career in sport career transitions with high performance athletes.

- Develop an ability to apply contemporary theory, research and practice to sport career transition profession.

- Understand the high performance environment and sport career transitions across sporting career of high performance athletes and coaches.

- Provide an opportunity to have professional practice experience in sport career transition.

\section{Section 3: Intended learning outcomes:}

Knowledge and Understanding

On successful completion of the curriculum, students should be able to demonstrate knowledge and understanding of:

- Primary theories and key research in sport career transitions

- Sport career transition intervention programmes across the world and the process of delivering the programmes to athletes

- The psychological needs for athletes' career transitions

- A multidimensional knowledge of psychological skills, strategies, and techniques in order to assist athletes in career transitions

- High performance sport policy and systems and High performance environment: culture, schedules/training timetables, coach expectations, agent influence, travel demands, age of entry, and average athlete life span.

\section{Subject-specific skills and other attributes}

- Apply a range of assessment methods in order to develop individualised plans of 


\begin{tabular}{|l}
\hline - \\
- Apply key sport career transition theories and research to practice in delivering \\
- Career transition support service \\
- Advanced communication skills (e.g. relationship and rapport building skills) in \\
order to build a network with relevant sporting organisations, educational \\
institutions, individual athletes, sponsors and media \\
- Develop an ability of targeting and marketing sport career transition support \\
services \\
Generic skills (e.g. information skills, communication skills, critical, analytical and \\
problem solving abilities) and other attributes: \\
- Develop an ability to work within a multi-disciplinary team \\
- Manage individual learning process and development \\
- Employ IT as an effective learning and communication tool \\
- Achieve effective oral, electronic, and written communication \\
- Develop both critical and creative thinking \\
- Acquire problem-solving and public speaking/presenting skills \\
- Enhance self-reflection \\
Section 4: Modules \\
- Career Transitions in Sport \\
- Sport Career Transition Management
\end{tabular}


Table 2

Changes of confidence in four competences in Study 3

\begin{tabular}{|c|c|c|c|c|c|c|c|c|c|c|c|c|}
\hline & \multicolumn{3}{|c|}{ Dual Career Transition } & \multicolumn{3}{|c|}{ Skill Transfer } & \multicolumn{3}{|c|}{ Social Support } & \multicolumn{3}{|c|}{ Career Planning } \\
\hline & \multicolumn{3}{|c|}{ Management } & & & & & & & & & \\
\hline & Pre & Post & Difference & Pre & Post & Difference & Pre & Post & Difference & Pre & Post & Difference \\
\hline Case 1 & 5.2 & 6.04 & +0.84 & 5.62 & 6.36 & +0.74 & 5.4875 & 6.4125 & +0.925 & 5.24 & 6.54 & +1.3 \\
\hline Case 2 & 5.99 & 9.39 & +3.4 & 5.64 & 9.29 & +3.65 & 5.475 & 9.025 & +3.55 & 4.82 & 9.64 & +4.82 \\
\hline Case 3 & 6.49 & 8.22 & +1.73 & 7.41 & 8.93 & +1.52 & 6.65 & 7.375 & +0.725 & 3.04 & 9.38 & +6.34 \\
\hline Case 4 & 6.27 & 8.89 & +2.62 & 6.6 & 9.02 & +2.42 & 6.8 & 9.1875 & +2.3875 & 5.74 & 8.44 & +2.7 \\
\hline
\end{tabular}




\section{Figures}

Figure 1

The Conceptual Model of Adaptation to Career Transition

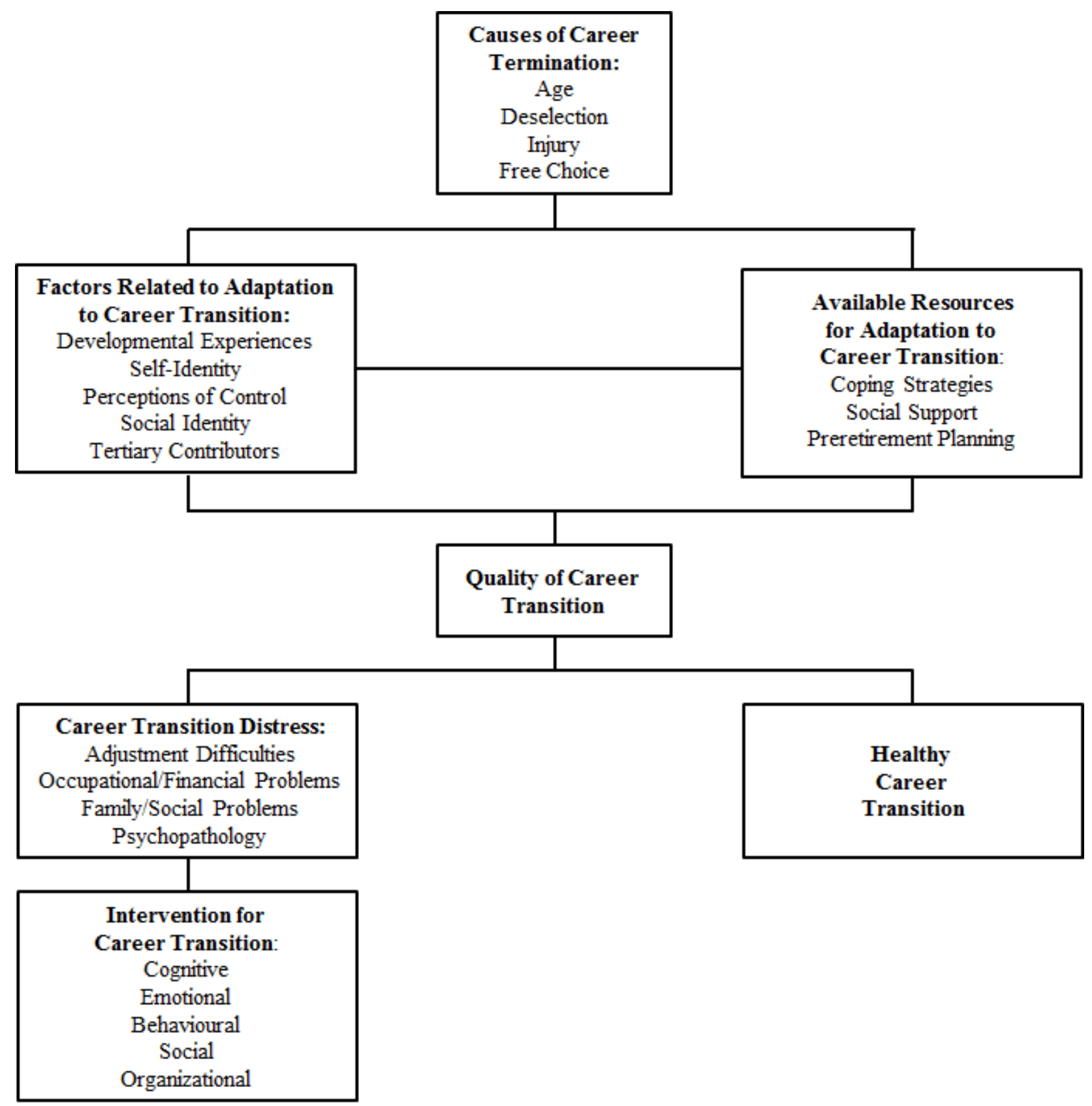

